\title{
Translational aspects in neurodevelopmental disorders
}

\author{
Tjitske Kleefstra ${ }^{1,2}$ \\ 'Department of Human Genetic and Donders Institute for Brain, Cognition and Behaviour, Radboud University Medical Center, \\ Nijmegen $6500 \mathrm{HB}$, The Netherlands. \\ ${ }^{2}$ Vincent van Gogh, Center for Neuropsychiatry, Venray 5800 AA, The Netherlands.
}

Correspondence to: Prof. Tjitske Kleefstra, Department of Human Genetics, Radboud University Medical Center, PO Box 9101, Nijmegen 6500 HB, The Netherlands. E-mail: tjitske.kleefstra@radboudumc.nl

How to cite this article: Kleefstra T. Translational aspects in neurodevelopmental disorders. J Trans/ Genet Genom 2020;4:464-6 http://dx.doi.org/10.20517/jtgg.2020.53

Received: 20 Nov 2020 Accepted: 20 Nov 2020 Available online: 26 Nov 2020

Academic Editor: Tjitske Kleefstra Copy Editor: Cai-Hong Wang Production Editor: Jing Yu

The past decade has impressively increased the diagnostic possibilities and outcomes for neurodevelopmental disorders (NDDs) ${ }^{[1-5]}$. Therefore, the scope of this Special Issue "Translational aspects in neurodevelopmental disorders" is broadened from gene and syndrome discovery to the clinical and biological understanding of defects underlying the NDDs. As over $50 \%$ of underlying genetic defects can now be identified in individuals with congenital neurodevelopmental problems, this provides challenges and opportunities for novel trajectories in clinical, molecular, and (fundamental) neurobiology fields.

Excellent studies that cover this broad scope have been peer reviewed and selected for publication in this Special Issue. Such studies are highly relevant to move this field forward from disorder causation to the understanding and intervention strategies on various aspects. The manuscript "Intellectual disability, the long way from genes to biological mechanisms" ${ }^{\text {"[6] }}$ describes several aspects in this broad trajectory. More classical genotype-phenotype studies are shown in two examples: "Spectrum of MECP2 mutations in Indian females with Rett Syndrome - a large cohort study" and "Assigning single clinical features to their disease-locus in large deletions: the example of chromosome 1q23-25 deletion syndrome" ${ }^{\text {, } 7,8]}$.

In addition to genomic technologies, important contributions to brain functioning can be provided by imaging modalities. The development and application of technologies that can explore important aspects of the anatomy, physiology, or biochemistry of the central nervous system are given and their properties, as well as pros and cons, are discussed in the context of several inborn errors of metabolism ${ }^{[9]}$.

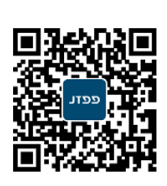


Tools that further define clinical and molecular phenotypes and may assist in molecular confirmation are shown by the use of facial recognition in "DeepGestalt analysis of the SETD5-associated intellectual disability syndrome" ${ }^{[10]}$ and by the application of DNA episigns in the study on several molecular variants causing Kleefstra syndrome in "EHMT1 pathogenic variants and 9q34.3 microdeletions share altered DNA methylation patterns in patients with Kleefstra syndrome" ${ }^{\text {"[1] }}$.

The involvement of molecular and biological pathways involved in NDDs are reflected nicely by two different reviews: "Role of transfer RNA modification and aminoacylation in the etiology of congenital intellectual disability" and "Chromodomain helicase DNA-binding proteins and neurodevelopmental disorders" ${ }^{[12,13]}$. The NDDs field increasingly benefits from the use of cellular and animal models, as reflected by the studies on "Human induced pluripotent cells in personalized treatment of monogenic epilepsies" ${ }^{\text {"14] }}$ and "Animal models of autism: a perspective from autophagy mechanisms" ${ }^{\text {"15] }}$. Finally, the manuscript "The influence of CYP enzymes and ABCB1 on treatment outcomes in schizophrenia: association of CYP1A2 activity with adverse effects" highlights the importance of pharmacogenomics on treatment of developmental or psychiatric conditions ${ }^{[16]}$.

Altogether, the studies presented in this special issue highlight the fascinating and rapidly moving field on understanding and treating Mendelian NDDs. Unique strategies are developed for optimal personalized medicine targeted to this vulnerable population.

\section{DECLARATIONS}

\section{Authors' contributions}

The author contributed solely to the article.

\section{Availability of data and materials}

Not applicable.

\section{Financial support and sponsorship}

Funding was provided by the Netherlands Organization for Health Research and Development (ZonMw grant 91718310 and research council (Aspasia 015.014.036).

\section{Conflicts of interest}

The author declared that there are no conflicts of interest.

\section{Ethical approval and consent to participate}

Not applicable.

\section{Consent for publication}

Not applicable.

\section{Copyright}

(c) The Author(s) 2020.

\section{REFERENCES}

1. Deciphering Developmental Disorders Study. Large-scale discovery of novel genetic causes of developmental disorders. Nature 2015;519:223-8.

2. Deciphering Developmental Disorders Study. Prevalence and architecture of de novo mutations in developmental disorders. Nature 2017;542:433-8.

3. Gilissen C, Hehir-Kwa JY, Thung DT, et al. Genome sequencing identifies major causes of severe intellectual disability. Nature 2014;511:344-7. 
4. Srivastava S, Love-Nichols JA, Dies KA, et al. Meta-analysis and multidisciplinary consensus statement: exome sequencing is a first-tier clinical diagnostic test for individuals with neurodevelopmental disorders. Genet Med 2019;21:2413-21.

5. Lelieveld SH, Reijnders MRF, Pfundt R, et al. Meta-analysis of 2,104 trios provides support for 10 new genes for intellectual disability. Nat Neurosci 2016;19:1194-6.

6. Marti M, Millan MIP, Young JI, Walz K. Intellectual disability, the long way from genes to biological mechanisms. J Transl Genet Genom 2020;4:104-13.

7. Khajuria R, Gupta N, van Roozendaal KEP, et al. Spectrum of MECP2 mutations in Indian females with Rett Syndrome - a large cohort study. J Transl Genet Genom 2020;4:91-103.

8. Fichera M, Saccuzzo L, Bertuzzo S, et al. Assigning single clinical features to their disease-locus in large deletions: the example of chromosome 1q23-25 deletion syndrome. J Transl Genet Genom 2020;4:114-32.

9. Gropman AL, Anderson A. Novel imaging technologies for genetic diagnoses in the inborn errors of metabolism. J Transl Genet Genom 2020;4.

10. Pascolini G. DeepGestalt analysis of the SETD5-associated intellectual disability syndrome. J Transl Genet Genom 2020;4:17-21.

11. Goodman SJ, Cytrynbaum C, Chung BHY, et al. EHMT1 pathogenic variants and 9q34.3 microdeletions share altered DNA methylation patterns in patients with Kleefstra syndrome. J Transl Genet Genom 2020;4:144-58.

12. Franz M, Hagenau L, Jensen LR, Kuss AW. Role of transfer RNA modification and aminoacylation in the etiology of congenital intellectual disability. J Transl Genet Genom 2020;4:50-70.

13. Yasin H, Zahir FR. Chromodomain helicase DNA-binding proteins and neurodevelopmental disorders. J Transl Genet Genom 2020;4:[Online First].

14. Mohammadi NA, Freude K, Haukedal H, et al. Human induced pluripotent cells in personalized treatment of monogenic epilepsies. $J$ Transl Genet Genom 2020;4:238-50.

15. Dana H, Tahtasakal R, Sener E F. Animal models of autism: a perspective from autophagy mechanisms. J Transl Genet Genom 2020;4:251-62.

16. Cendrós M, Arranz MJ, Torra M, et al. The influence of CYP enzymes and ABCB1 on treatment outcomes in schizophrenia: association of CYP1A2 activity with adverse effects. $J$ Transl Genet Genom 2020;4:210-20. 